\title{
MACBETH: LA TRAGEDIA DEL SUEÑO ${ }^{1}$
}

\author{
Martin von Koppenfels \\ Ludwig-Maximilians-Universität München \\ München, Alemania \\ koppenfels@1rz.uni-muenchen.de
}

\section{RESUMEN / ABSTRACT}

Macbeth de Shakespeare en la investigación frecuentemente es calificado en un sentido más bien vago, atmosférico, como una pieza "de pesadilla". Esta intuición puede concretizarse y remitir al carácter de género de la pieza. El drama de Shakespeare resulta, al igual que determinadas tragedias antiguas (concretamente, la 'Orestíada' de Esquilo), como prueba de la tesis de que la tragedia en tanto género representa uno de los lugares en los que la literatura busca la aproximación a la experiencia de la pesadilla. Sobre todo la función perturbadora y destructiva del sueño que le es propia a la pesadilla en el Macbeth representa un motivo directriz que influye la pieza hasta su misma estructura. La lectura presente analiza el entramado de metáforas que rodea a esta fantasía con remisión a Melanie Klein en el sentido de la representación de objetos interiores fantaseados. La manera en que tales fantasías son simbolizadas en 'Macbeth' arroja una luz sobre la función de la poesía trágica en general.

Palabras ClaVE: Macbeth, Shakespeare, tragedia, pesadilla, objeto interior.

\section{"MACBETH": THE TRAGEDY OF SLEEP}

In scholarly studies, Shakespeare's Macbeth is frequently referred to in a vague, atmospheric sense as a "nightmare" play. This intuitive insight is susceptible of substantiation; the genre of the play is the key. Like a number of ancient tragedies (notably Aeschylus ' "Oresteia"), Shakespeare's drama provides evidence for the theory that tragedy as a genre is one of the loci where literature seeks an approach to the experience of nightmare. In Macbeth the disruptive and destructive function of nightmare is a leitmotif that leaves its imprint on the play right

1 Traducción del alemán de Niklas Bornhauser. Publicación original: Martin von Koppenfels "Macbeth: die Tragödie des Schlafs". Angst, número especial de Psyche 69 (2015): 962-984. 
down to the structural level. Here the fantasy of the »murder of sleep " plays a crucial role. With explicit reference to Melanie Klein's fantasized internal objects, the author analyses the concatenation of metaphors surrounding this fantasy. The way in which such fantasies are symbolized in Macbeth casts light on the function of tragic literature in general.

KEYWORDS: Macbeth, Shakespeare, tragedy, nightmare, sleep, internal object.

Recepción: 13/11/2020

Aprobación: 07/12/2020

\section{MATAR EL SUEÑO}

En su tragedia más sombría, Shakespeare incorpora quizá el mayor elogio del sueño jamás escrito por un poeta:

Methought, I heard a voice cry, >Sleep no more!

Macbeth does murther Sleep, $<-$ the innocent Sleep;

Sleep, that knits up the ravell'd sleave of care,

The death of each day's life, sore labour's bath,

Balm of hurt minds, great Nature's second course,

Chief nourisher in life's feast [...] (II, 2, 34-39) ${ }^{2}$

Esta es la primera alucinación acústica de Macbeth; sigue inmediatamente a su primer asesinato - del rey Duncan, al que apuñala mientras duerme- y pertenece, junto a la visión de la daga que precedió a este asesinato, a los primeros indicios de un incipiente desquiciamiento. Esta voz ominosa, mitad demonio mitad conciencia moral, ya al inicio de su carrera como delincuente introduce la acción contraria que -dado que en la Tragedy of Macbeth no hay un antagonista que pueda ser tomado en serio (McElroy 272)- solo puede empezar a abrirse paso en él mismo. Ella enuncia que la sentencia sobre él ya ha sido proclamada: bajo la forma de la autodestrucción que arranca en las profundidades de la psicosomática, como frustración infinita de la más fuerte de todas las necesidades: la necesidad de dormir. Pero esta voz no se conforma con dar a conocer el juicio. No se conforma con la triple maldición que condena a cada uno de los nombres del héroe, uno por uno: "Glamis hath murther'd Sleep, and therefore Cawdor / Shall sleep no more, Macbeth shall

2 Creí escuchar una voz que me decía: "Macbeth, tú no puedes dormir, porque has asesinado al sueño”. ¡Perder el sueño, que desteje la intrincada trama del dolor, el sueño, descanso de toda fatiga: alimento el más dulce que se sirve a la mesa de la vida! 
sleep no more!" (II, 2, 41f.) $)^{3}$. Además, también encuentra el tiempo necesario para entonar un verdadero himno, en el que el sueño aparece como víctima y deidad a la vez ${ }^{4}$. Como víctima, el sueño se funde tanto con el rey Duncan, que duerme indefensamente, así como con su asesino que, al derramar su sangre, se asesinó nada menos que a sí mismo [Hand an sich selbst gelegt], es decir, a su propia conciencia moral. Como deidad, el sueño se convierte en poder curador y protector $-\mathrm{y}$, con esto, al interior del sistema mitológico de la tragedia, en instancia contraria a todo lo que representan las brujas o las "Weïrd Sisters". Y, de hecho, la destrucción del sueño, junto a otras prácticas oscuras, pertenece a las obligaciones de las "Weïrd Sisters" a las que Macbeth está sometido (I, 3, 19). En espesa retórica, el himno enumera las bondades del dormir (pero que son, en estricto sentido, propias del soñar) y anuda al dormir firmemente con los campos imaginarios 'tejido' y 'nutrición'. La última asociación representa una respuesta a la perversa metafórica, de parte de Lady Macbeth, de la leche materna, que ha ocupado la fantasía de los lectores desde siempre. Complementa la serie de metáforas dormir -telaleche, que en el pensamiento de esta tragedia juega un rol central.

Macbeth también es, aparte de muchas otras cosas, la tragedia de la arquitectura alterada del dormir (para pedir prestado un término de la somnología moderna). Ahora, los trastornos del sueño ya en la Antigüedad son "una señal de estatura trágica" (Noll 132). Ya en las historias de Shakespeare el insomnio pertenece al rey al igual que la corona y, en cierto modo, conforma su forro interior torturador ${ }^{5}$. Y mientras más ilegítimo el dominio, peor: "El tirano está en vela, eso lo caracteriza por antonomasia" dice Emil Cioran (137). Pero Shakespeare, en Macbeth, de un topos ya gastado, extrae, de imprevisto, un drama fascinante sobre la tiranía que obra entre cuerpo y alma. El insomnio

\footnotetext{
“Glámis ha matado al sueño: por eso no dormirá Cáudor, ni tampoco Macbeth”. En lo que sigue, en ocasiones se le dará la preferencia al original inglés por sobre la traducción, en particular cuando esta última, ya sea en un sentido formal o semántico, no se corresponda del todo con el argumento. En este caso, ni la traducción al alemán de Frank Günther ni las principales traducciones al castellano consultadas logran expresar plenamente el ritmo balanceante de la triple maldición.

Kenneth Muir (1984) en su comentario remite al episodio del dios Morfeo en Ovidio, Metamorfosis, XI, 624f.

Cfr. 2 Henry IV, 5-31 y Henry V, IV, 272-290. En el primero de los dramas también ya se encuentra el tratamiento hímnico ("O sleep, O gentle sleep") que a su vez remite al soneto de Sidney “Come, Sleep; O Sleep!”. Cfr. la observación en Shakespeare 2005 (1623), p. 89.
} 
de Macbeth y el célebre sonambulismo de su esposa crean fusiones entre pathos y patología, a través de las que algo tan inasible como el dormir de repente es puesto en el centro de la trama trágica, incluso se convierte, él mismo, en actor dramático.

El verso "Sleep, that knits up the ravell'd sleave of care" [y que, en ocasiones, ha sido traducido como: Sueño que devana una maraña de desvelos] ha sido adoptado como una especie de lema por la investigación del dormir y del sueño. Shakespeare se convierte en patrono de la teoría del efecto curador del soñar como un articular lúdico de redes mentales ${ }^{6}$. "Sleave" es una palabra elisabetana para 'madeja', pero también para un tipo de seda tejido de manera suelta - habría que traducir, entonces: "Sueño, que retoma los hilos desgreñados del cuidado"7. Todo esto arroja la pregunta de cómo se comporta este trabajo de cura textil respecto del trabajo del texto que leemos; más precisamente, si es que existe una relación entre la fisiología del sueño pasando por la psicología del sueño hacia la poética.

\section{POÉTICA Y PESADILLA}

El que en esta tragedia se hable tanto del dormir tiene que ser considerado en relación con otra propiedad del drama, a saber, su atmósfera de pesadilla. El adjetivo "nightmarish" pertenece a las palabras más frecuentes en la inabarcable literatura sobre Macbeth (por ejemplo, McElroy 209; Wilbern 533). En la investigación aparentemente existe una especie de consenso sentimental de que aquí uno se las tiene que ver con una pesadilla escenificada -"a waking nightmare" . Este consenso, al mismo tiempo vago e implícito, es algo que quisiera concretizar en lo que sigue. Concierne, así mi tesis, no solo la atmósfera, sino también el carácter del género de la pieza.

6 Por ejemplo, Ernest Hartmann 2001 (1998), p. 15.

La idea del "Aufdröseln" [desenredar o desenmarañar] que el traductor al alemán Frank Günther pone en juego en este lugar conduce al equívoco. "Knitting up" es un acto que une, no uno que disuelve. La traducción de Günther "Sueño, que desenmaraña la madeja de preocupaciones enredadas" prácticamente invierte en su contrario al sentido de la cita. Sigue en este punto, reforzándola, a la traducción de Tieck: "Sueño, que desenreda el hilado de la confusa aflicción".

Wilson Knight 1931, p. 148. "The play's action has been all along a waking nightmare". Weidhorn 1970, p. 117: "life as a nightmare”. Cfr. también Lesser 1976. 
La lectura de Macbeth que sigue se encuentra en el contexto de una pregunta, que conduce más allá, sobre la relación entre pesadilla y tragedia ${ }^{9}$. Parte del supuesto de que la tragedia, en tanto género, representa uno de los espacios en los que la literatura busca la aproximación a la experiencia de la pesadilla -en el sentido de un valor liminal alrededor del que gira el género, pero que nunca debe alcanzar. Con esto nos encontramos en el campo de fuerzas de la llamada "paradoja trágica", la pregunta, ya planteada por Aristóteles, de por qué lo displacentero, representado de cierta manera, puede ser recepcionado con placer. Una paradoja que ciertamente no es tal, si se entiende el drama como trabajo artístico que apunta a la simbolización de experiencia emocional. Parto de que entre el problema de la pesadilla y aquel de las emociones negativas en escenarios dramáticos y ficticios en otro sentido existe una relación funcional y que esta relación pueda ayudar a comprender el trabajo que hacen textos literarios en el campo de los afectos negativos. Así como la pesadilla cuestiona un modelo del sueño que está basado en un concepto demasiado simple del cumplimiento de deseo, así la tragedia, una y otra vez, desafía teorías del arte "hedónicas", es decir, basadas en un concepto demasiado simple de placer.

Trabajar con esta analogía, sin embargo, supone atribuir a los sueños un rol en la elaboración de emociones -algo que en ningún caso es algo evidente o comprensible de suyo. En el caso de La interpretación de los sueños freudiana, por ejemplo, dos de sus axiomas impedían lo anterior - la tesis del carácter de cumplimiento de deseo y la determinación funcional del sueño como "guardián del sueño". Por consiguiente, no resulta sorprendente que Freud haya declarado a la "inhibición afectiva" como característica estructural del sueño (Freud, La interpretación 471$)^{10}$. No podía asignarle una función autónoma al caso extremo de un sueño gravado afectivamente, al sueño de angustia o a la pesadilla ${ }^{11}$, sino tan solo comprenderlo como efecto del fracaso de otra función. En cambio, si se está dispuesto a asumir la existencia de una función del sueño que elabora las emociones, entonces, la pesadilla de fenómeno marginal pasa a ser espectacular piedra de toque de la teoría de los sueños. Si es que los sueños son productos de un pensamiento

$9 \quad$ Cfr. Koppenfels 2014.

$10 \quad$ Sobre esto: Koppenfels 2012.

11 Me permito, en un sentido coloquial, usar a ambos conceptos como sinónimos. Freud consecuentemente prefirió el concepto de "sueño de angustia". 
inconsciente que resuelve problemas, que, entre otros, procesa experiencias emocionales, entonces, el concepto de la pesadilla representa una alteración del pensamiento onírico, la indefensión [Hilflosigkeit] de este pensamiento de cara a una inundación mediante la angustia. La consecuencia de este desbordamiento es el despertar que distingue a la pesadilla categóricamente de otras formas del soñar angustiado; el despertar como ultima ratio y fuga del horror [Schrecken] soñado al precio de la renuncia a la regresión placentera del sueño.

Textos poéticos, así la tesis, tienen, entre otras, la función de mantener el contacto con aquel pensar onírico que está gravado elementalmente con experiencia emocional. Bajo esta presuposición sería curioso que la poesía se cerrara justamente a aquellas fantasías que cargan el peso emocional más pesado. Y estas son, sin lugar a dudas, las fantasías a partir de las que están hechas las pesadillas. El género tragedia que desde sus inicios (Persas y Orestíada de Esquilo) se dedica reflexivamente, también a nivel de contenido, a los sueños de angustia, puede ser comprendida como elaboración consciente, análoga a los sueños, de tales fantasías de angustia. Las tragedias, en ese caso, serían productos de un trabajo de simbolización que es realizado a partir de socavamientos colectivos o sus respectivas fantasías y que sirve a su superación mediante el pensamiento. Su función consistiría en ayudar a elaborar, el sueño mediante [abträumen], las pesadillas colectivas (Freud, Der Dichter 222) en relación al mito habla en una ocasión de los "sueños seculares" de la humanidad). Elaborar, el sueño mediante, a la angustia - esta es una determinación funcional que ya el fundador del psicoanálisis sopesaba para cierta clase de pesadillas, a saber, los sueños postraumáticos ${ }^{12}$. En esto, se trataba, para él, de reconocer un sentido y una función en el carácter repetitivo y atormentador de tales sueños.

Sin embargo, las tragedias no solo repiten, sino que también complementan: es probable que una función central de la trama trágica consista en soñar la pesadilla hasta el final. Finalmente, las pesadillas son estructuras simbólicas dañadas: al despertar al soñante, producen un transcurso simbólico que se interrumpe a sí mismo. Incluso cuando parecen ser insoportablemente largas, siempre terminan demasiado temprano -antes de que el pensamiento onírico haya logrado darle un giro soportable al susto. Uno podría especular que

12 "Estos sueños buscan recuperar el dominio [Bewältigung] sobre el estímulo por medio de un desarrollo de angustia" (Freud 1920g, p. 31). 
esta autosuspensión es la rasgadura que es elaborada o transformada en la tragedia. Si esto fuera cierto, la tragedia en relación con nuestra economía fantasiosa inconsciente tendría una función reparadora, parecida a la que Macbeth le atribuye al dormir ${ }^{13}$.

\section{LA TRAGEDIA INSOMNE}

Macbeth es una obra que no puede obviarse cuando uno se interroga por la relación entre tragedia y pesadilla. El éxito único de este drama quizá reside precisamente en que, de camino hacia la pesadilla, va más allá que cualquier tragedia antes de él. Un primer indicio para esto es el apresurado dénouement, con el que al final, en unos pocos versos, el mundo que se ha salido de quicio es vuelto a ser rectificado, los malos son liquidados y el reino legitimo es restaurado. Este final produce la impresión de un retorno, involuntario y solo realizado pro forma, "a la medida al tiempo y al lugar" y al orden indulgente, conciliador de "la palabra" y "del dios misericordioso" (V, 9, 38f.).

No obstante, emerge una dificultad si uno se aproxima a la obra con esta tesis: en Macbeth, la pesadilla en tanto motivo trágico parece estar en retirada. Mientras que sueños proféticos de desgracia desde Esquilo pertenecen al inventario del pathos de la tragedia, Macbeth aparentemente es un drama sin sueños. Si bien de pasada escuchamos que el héroe sufre de pesadillas permanentes ("de los sueños espantosos que me agitan / cada noche (III, 2)), pero aquí no hay relatos cautivadores como, por ejemplo, en Las Coéforas de Esquilo o en Ricardo III de Shakespeare. La obra tampoco contiene representaciones escénicas de sueños, tal como es el caso en Las Euménides o, nuevamente, en Ricardo III. La única excepción la conforma la escena sonámbula de Lady Macbeth y esta solo muestra el actuar de su cuerpo bajo la influencia de un sueño terrible, pero no a este sueño mismo. Es como si Esquilo al comienzo de Las Euménides solo hubiera llevado a la escena el ladrar y gemir de las Erinias durmientes, pero no la figura de la Clitemnestra que se les aparece en sueños. El único que relata un sueño en la pieza es justo el antagonista de Macbeth, Banco: “Anoche soñé con las tres

13 La llamada "Image Rehearsal Therapy", una aproximación terapéutica que apunta a refantasear los escenarios de la pesadilla, puede ser entendida como una versión para el uso casero de este trabajo dramático. Cfr. Krakow et al. 1996. 
Hermanas Fatídicas" (II, 1). Esta información no es precisamente exhaustiva, pero será un detalle de suma importancia que Banco logra soñar con las tres brujas, mientras que Macbeth tiene que repetir el encuentro con ellas.

La respuesta a la objeción recién formulada ha de decir: justamente porque en Macbeth no hay sueños que lleguen a la representación, es que todo el drama se convierte en pesadilla. Al robarles el sueño a ambos protagonistas, Shakespeare coloca justamente a ese en el centro de la atención y a través de esto vuelve a colocar al trauma y a la trama dramática en una nueva relación: todos los asesinatos - exceptuando el primero-son cometidos con tal de poder soñar. La obra imita, a través de su estructura, el estrés del dormir alterado. Donde este fracasa, fracasa el sueño. No es de sorprender que en lugar de sueños se presenten alucinaciones: la visión de la daga, las distintas voces, la aparición del espíritu de Banquo. La realidad comienza a deformarse, la misma tierra comienza a arrojar burbujas $(\mathrm{I}, 3,79)$ y da a luz a las "Weïrd Sisters" que, a su vez, producen otras visiones más, hasta que al final incluso bosques enteros pasan al ataque. Si pertenece a la sintomática de lo trágico el que la frontera entre sueño y vigilia se vuelva más permeable de lo que le conviene a los hombres, entonces esta pieza, que exhibe rasgos psicóticos, también en este aspecto representa un extremo. Porque a Macbeth le falta el espacio de proyección del dormir y del sueño, cae en una escalación que en la historia del drama no tiene igual.

No solo Macbeth asesina al dormir, también lo hace Shakespeare. Lo que presenta en la escena del sonambulismo de Lady Macbeth no es sino un ataque al "lugar seguro" (Hartmann 2001) del dormir: en la medida en que la pesadilla aquí supera la parálisis motora del estado del dormir, escapa de este lugar seguro y desde la escena del sueño se extiende hacia el escenario de la vida; precisamente ante un público, porque la sleep walking scene, en la que el actuar, carente de conciencia, de Lady Macbeth es observado y comentado por dos testigos, es la escena central de pieza-al-interior-dela-pieza de esta tragedia. Partiendo de esta escena emblemática es posible interpretar la estructura temporal de toda la pieza: Se trata de la más corta de todas las tragedias de Shakespeare (Muir XIII); nos la tenemos que ver con una vertiginosa maquinaria de la angustia, que, sin dejar respirar, acumula asesinato tras asesinato. La impresión de la falta de aliento ${ }^{14}$ se produce a

14 La falta de aliento efectivamente es un Leitmotiv del drama, por ejemplo, en I, 2, 42 y I, 5, 35. Pero, la falta de aliento es, también, un elemento principal, como apnea, de la 
partir del deseo frustrado del héroe de terminar con todo ( $c f r$. Booth 93). Macbeth, el que no puede decir amén (II, 2, 28), asesina contra la infinitud: "tomorrow, and to-morrow, and to-morrow" (V, 5, 19). Esta pujanza desesperada hacia el final, que tanto acelera a la pieza, puede entenderse como resultado de la incapacidad de despertar de una pesadilla desbordada - una paradoja maligna, pues las pesadillas se caracterizan justamente por el hecho de que despiertan al soñante.

El símbolo de esta paradoja es la campana de alarma (alarum bell) que en la pieza suena una y otra vez: por un lado, el estridente despertador permanente del susto que a todos les roba el sueño, por el otro, parte repetitiva de la pesadilla y en tanto tal incapaz de terminar a éste. Como reflejo interno de esta lucha por el despertar Shakespeare incorporó a la escena del portero (II, 3, 1-41) al drama: como único momento de comic relief en una tragedia que no tiene tiempo para lo cómico ${ }^{15}$. Sin embargo, si se contempla la pieza bajo el aspecto del límite alterado entre el dormir y el despertar, la escena del portero aparece altamente funcional: como escenificación del atormentador despertar aplazado, que quizá nunca se logre, del sueño de horror de la noche del asesinato ${ }^{16}$. El portal del castillo, desde este punto de vista, es también el portal mítico del dormir. Y el teatro se convierte en fuerte del dormir, que es penetrado desde el exterior (desde detrás del escenario) por un estímulo ${ }^{17}$. El impaciente golpeteo en el portal del castillo de Macbeth suena desde un exterior lejano, aparentemente inalcanzable, hacia la escena, mientras que el portero borracho, despierta a duras penas y en el limbo entre el dormir y el

fenomenología tradicional de la presión [Druck] causada por elfo nocturno [Alp], asociada a la pesadilla [Alpdruck].

15 Es por esto que la escena en ocasiones es considerada apócrifa. Cfr. Muir 1984, XXV.

El que esta muerte de asesinatos representa una esfera separada de la conciencia del día a día es una hipótesis a la que también apunta la lectura de Thomas De Quincey. Su descripción se aproxima al concepto de pesadilla todo lo posible, sin emplearlo: "Asesinos y asesinato tienen que ser aislados - apartado mediante una zanja inconmensurable del ir y venir del quehacer humano y encerrado en un profundo retiro; uno tiene que sentir que el mundo de lo común y corriente de repente se detiene, cae en sueños, en trance, se petrifica en un terrible cese al fuego; el tiempo tiene que ser borrado, toda conexión con el mundo exterior cortada y todo, replegado en sí mismo, tiene que caer en un profundo desmayo, olvidando lo terrenal" (De Quincey 1986 [1823], p. 9f.).

17 "El estado del dormir garantiza la seguridad de la fortaleza en custodia" (Freud 1900a, p. 559). En Freud, esta fortaleza es amenazada desde el interior - y no, como sucede en Shakespeare, desde el exterior. 
despertar se interpreta así mismo en tanto figura de un mystery play: como guardián diabólico en la puerta al infierno, que recibe a las almas condenadas. Pero el infierno alegórico es mucho menos terrible que el infierno realizado del drama. La pointe de esta alegoresis alcoholizada consiste en que al mismo tiempo tacha el despertar en aquel momento en el que sucede y lo reemplaza por otro despertar, uno escatológico. En tanto escena del despertar la porterscene es una falsa pista, porque la pesadilla sigue inmediatamente después. El final del sueño es aplazado hasta el día del Juicio Final. Macduff, que ingresa al castillo durmiente hacia el final de esta escena, de inmediato entregará la variante trágica de esta pointe, cuando, después de haber descubierto al rey asesinado, despierta a los vivientes como si fueran los muertos el día el Juicio Final:

Shake off this downy sleep, death's counterfeit, And look on death itself! - up, up, and see The great doom's image! - Malcolm! Banquo! As from your graves rise up, and walk like sprites, To countenance this horror! (II, 3, 75-79) $)^{18}$.

Una tragedia, que ataca al dormir y al sueño, se ataca a sí misma. Al asesinar al dormir (y con ello también al sueño), Macbeth en última instancia asesina al principio imaginario del teatro de Shakespeare. La trama de la obra en consecuencia evoca la impresión de un tour de force, que tan solo a regañadientes se somete a las convenciones dramáticas. Sin embargo, como fuerza opuesta, Shakespeare recubrió esta trama vertiginosa con una red, finamente hilvanada, de simbolismo lingüístico: Macbeth asesina como Ricardo III pero habla como Ofelia. Su lenguaje posee una cualidad hipnoide. Se podría decir: el soñar, al que ya no tiene acceso, penetró su lenguaje. La resultante desintegración del habla es su gran fortaleza. Esta escisión (una escisión en el sentido estricto de la palabra) lleva a que, mientras más avanza la pieza, Macbeth aparezca cada vez más como un sonámbulo. La escisión del simbolismo lingüístico de la trama contribuye no poco a la impresión pesadillesca de la tragedia-pero,

18 " $i$ Sacudid el grato sueño, / imagen de la muerte, y mirad / la muerte verdadera! ¡Levantaos y ved / representado el Dia del Juicio! ¡Malcolm! ¡Banquo! / ¡Como espíritus alzaos de las tumbas / y prestad consonancia a este horror!". 
en realidad, asegura que ésta nunca se convierta del todo en pesadilla, sino que siga siendo tragedia, es decir, obra de arte lingüística.

\section{DORMIR - LECHE - TELA}

Para esta tragedia vale lo que Karl Kraus dice de las palabras: mientras más de cerca uno las mire, más lejos ellas miran de vuelta. De manera aparentemente independiente del curso de la trama aquí se arma un entramado de metáforas que sigue sus propias leyes e inviste el sueño del ascenso y de la caída de Macbeth con fantasías. Si se siguen las líneas asociativas que de ahí se desprenden, no puede evitarse descomponer y volver a componer el texto, porque estas conexiones con frecuencia transcurren de manera transversal a la línea de la trama. Dos de los elementos de este entramado representacional son particularmente interesantes: la leche y la tela. Ellos están unidos de lo más estrechamente con el complejo ‘dormir y sueño’ y salen al encuentro ya en el himno citado de entrada: "Sleep, that knits up the ravell'd sleave of care / [...] great Nature's second course, / Chief nourisher in life's feast [...]"19. Aquí el dormir aparece no solo como trabajador de textiles que repara telas defectuosas, sino que también como el gran alimentador que amamanta la vida ("second course" es el sustancioso plato principal de un festín). Poco después Macbeth volverá a establecer una asociación entre nutrición y dormir:

But let the frame of things disjoint, both the worlds suffer,

Ere we will eat our meal in fear, and sleep

In the affliction of these terrible dreams,

That shake us nightly

(III, 2, 16-19) ${ }^{20}$.

Esta conexión es cualquier cosa menos casual. La idea del dormir como "chief nourisher" más bien conduce directamente a uno de los núcleos fantasmáticos de la pieza -las fantasías de maternidad perversa, que le están inscritas al

19 "El sueño que devana una maraña de desvelos, / [..] plato fuerte / de la gran naturaleza, sustento mayor / del festín de la vida".

20 "Que se hunda todo el universo / que perezcan ambos mundos antes que tomar / alimento en el temor y dormir en la tortura / de los sueños espantosos que me agitan / cada noche". 
texto, de manera vistosa, a través de la figura de las tres brujas y de Lady Macbeth, y que de manera correspondiente atrajeron mucha atención. Esto es comprensible, porque estas figuras, sin lugar a dudas, son escandalosas. Pero una lectura que, por ejemplo, solo destaca el carácter misógino de estas fantasías, permanece en la superficie. Porque Shakespeare aquí abre, como ha de ser mostrado en el apartado siguiente, miradas hacia el interior de un mundo arcaico de fantasía, que en cierto sentido está arraigado antes de toda imaginación sexualmente diferenciada.

Si es que Macbeth, luego del primer asesinato, califica al dormir como "chief nourisher", entonces reacciona a las fantasías, espectacularmente perversas, de pecho materno en los grandes monólogos precedentes de su mujer:

Come, you Spirits

That tend on mortal thoughts, unsex me here,

[...] Come to my woman's breasts,

And take my milk for gall, you murth'ring ministers

$(\mathrm{I}, 5,40-48)^{21}$.

I have given suck, and know

How tender 'tis to love the babe that milks me:

I would, while it was smiling in my face,

Have pluck'd the nipple from his boneless gums,

And dash'd the brains out, had I so sworn

As you have done to this

$(\mathrm{I}, 7,54-59)^{22}$.

Esta fantasía de asesinato infantil (en la que la hablante se pone en una serie con Medea de Seneca ${ }^{23}$ ) encuentra una correspondencia en la decocción infernal de las brujas, a cuyos ingredientes, aparte de diversas otras partes de cadáveres, también pertenece material de un neonato asesinado (IV, 1, 30) - por lo que David Willbern ha calificado a este caldero infernal como "fatal maternal enclosure" (Wilbern 542). En el futuro transcurso del drama la misma Escocia, el escenario, envenenado por brujería, de la pieza, se convierte

21 "Venid a mí, espíritus / que servís a propósitos de muerte, quitadme la ternura, / [...] Venid a mis pechos de mujer / y cambiad mi leche en hiel, espíritus del crimen".

22 "Yo he dado el pecho y sé / lo dulce que es amar al niño que amamantas; / cuando estaba sonriéndome, / habría podido arrancarle mi pezón de sus encías / y estrellarle los sesos si lo hubiese jurado / como tú has jurado esto".

23. Cfr. Ewbank 1977, pp. 54-56. 
en semejante cárcel materna mortal: "It cannot / Be called our mother, but our grave" 24 (IV, 3, 166). No obstante, aquí me interesa en un principio ni la angustia del descuartizamiento ni la claustrofobia, sino el hecho de que en los dos pasajes citados, el pecho materno aparece como lugar de la muerte. Alimentar(se) es mortal en el mundo de Macbeth: los asesinatos ahí tienen lugar de preferencia después o durante banquetes. Y la leche desnaturalizada, vuelta incomible, juega un rol en general en la pieza: los sirvientes del rey son anestesiados con una bebida envenenada para conciliar el sueño (II, 2, 6) ${ }^{25}$. Este mundo de manera inquietante es intolerante a la lactosa: Lady Macbeth le reprocha a su marido que "está muy empapado de leche de bondad para tomar los atajos" (I, 5, 17). Aquí vale la divisa: "al infierno la leche de la concordia" 26 (IV, 3, 98) y "whey-face" (cara de suero de leche) es un insulto para un cobarde $(\mathrm{V}, 3,17)^{27}$.

Fantasías de pecho materno también se encuentran en Macbeth bajo la forma de metáforas arquitectónicas -sobre todo en la descripción del castillo Inverness de Lady Macbeth, ese lugar presuntamente seguro que resulta ser una trampa mortal ${ }^{28}$ : "The raven himself is hoarse, / That croaks the fatal entrance of Duncan / Under my battlements" ${ }^{29}$ así dice el comienzo del monólogo en el que ella llama a los espíritus del infierno hacia sus pechos (I, 5, 38-40). Esta relación fantasmática se vuelve particularmente evidente en otro pasaje, casi inmediatamente posterior: el desprevenido rey Duncan

24 "Ya no puede / llamarse nuestra madre, sino nuestra tumba".

$25 C f r$. Muir 1984, p. 51, respecto de la composición, rica en leche, de la poción (posset).

26 Esta divisa es parte del autofingimiento o disimulación del legítimo heredero del trono Malcolm - una imitación del mundo de Macbeth.

$27 \quad$ En Description of Scotland de Holinshead, una de las principales fuentes de la obra, Shakespeare pudo encontrar una observación sobre la singular actitud de la nobleza escocesa hacia la leche materna, según la que en estos círculos la contratación de una nodriza era considerada como signo de infidelidad conyugal, por lo que las mujeres hacían todo lo posible para poder amamantar, ellas mismas, a sus propios hijos: "Each woman would take intollerable paines to bring up and nourish her own children. They thought them furthermore not to be kindlie fostered, except they were so well nourished after their births with the milke of their brests, as they were before they were borne with the bloud of their owne bellies, nay they feared least they should degenerate and grow out of kind except they gave them sucke themselves, and eschewed strange milke" (citado según Muir 1984, p. 180).

$28 \quad$ Cfr. Wilbern 1986, p. 524.

29 "Hasta el cuervo está ronco / de graznar la fatídica entrada de Duncan / bajo mis almenas". 
se aproxima al castillo y alaba la atmósfera pura y saludable del lugar. Y su acompañante Banquo replica con una pieza de lírica natural que se detiene, en apariencia sin función alguna, en el espacio dramático:

This guest of summer,

The temple-haunting martlet, does approve,

By his loved mansionry, that the heaven's breath

Smells wooingly here: no jutty, frieze,

Buttress, nor coign of vantage, but this bird

Hath made his pendent bed, and procreant cradle:

Where they most breed and haunt, I have observ'd

The air is delicate

$(\mathrm{I}, 6,4-10)^{30}$.

En admirable condensación aquí se alojan distintos estratos representacionales. En un principio, la metafórica del pájaro, que atraviesa todo el texto del drama: el cuervo fatal de Lady Macbeth se les aparece a las víctimas inadvertidas como dulce golondrina ${ }^{31}$-uno de tantos signos engañosos en la pieza. Está, además, la oposición, fundamental para la pieza, entre el aire puro y el aire contaminado; fundamental porque este último forma el elemento vital de las brujas ("hover through the fog and filthy air" - I, 1,11) y son escenas del respirar libre en este mundo embrujado. Estas metáforas naturales literalmente solo representan una entrada para otra cosa. Sirven para describir la sexualización del edificio: los "battlements" de Lady Macbeth reaparecen bajo la figura de una serie de prominencias arquitectónicas ("jutty", "frieze", "buttress", "coign of vantage"). A estas se les adhiere un espeso escenario de la fertilidad, de la procreación y del nutrir: "loved", "wooingly", "pendent bed", "procreant cradle", "breed", etc. Y eso en un drama que, como ya supo reconocer Freud, está obsesionado por el tema de la falta de niños (Freud,

$30 \quad$ "El huésped del verano / el vencejo que ronda las iglesias, nos demuestra / con su amada construcción / que el hálito del cielo / aquí seduce de fragancia: no hay saliente, friso, / contrafuerte o esquina favorable en que este pájaro / no haya hecho su colgante lecho y cuna. / He observado que donde más anida y cría / el aire es delicado".

31 Ornitológicamente no del todo preciso: "martlet" en el inglés temprano designa un vencejo común. En todo caso, la confusión con la golondrina o el avión común ("house martin") parece haber sido habitual. 
Einige Chraraktertypen 373-380). El discurso de Banquo proyecta sobre el castillo de Lady Macbeth (su cuerpo) todo lo que ella no tiene ${ }^{32}$.

No obstante, a esto se agrega un tercer aspecto de significación de este lugar -a saber, uno blasónico: en la heráldica inglesa, "martlet" designa la imagen de un pájaro que se asemeja a una golondrina, sin pies- en cierto modo, un puro ser del aire que nunca toca al suelo. Este motivo ya aparece en el blasón de Edward the Confessor ${ }^{33}$, justo el rey sacralizado que en Macbeth es evocado como imagen contraria idealizada, como encarnación de la monarquía que promete prosperidad y salvación. El público de Shakespeare acaso podría haber visto los pájaros heráldicos en cuestión en Westminster Abbey, fundada precisamente por Edward, donde son un motivo frecuente (de ahí quizá el "temple-haunting martlet"). Por lo tanto, los pájaros del cielo están estrechamente entrelazados con el mito inglés de la salvación real, que en el borde de la tragedia escocesa brilla como luminosa imagen contrastante. En esta escena son asociadas con el buen rey Duncan, que aquí cabalga hacia el matadero, pero sobre todo con Banquo, que pronuncia los versos citados. En tanto progenitor mítico de Jacobo I, para quien Macbeth fue representado (Muir XXIII), él en este drama es el representante de la monarquía que traerá la salvación.

El tercer y último elemento del complejo metafórico nombrado más arriba -la tela- también forma un Leitmotiv del texto: ya en la primera mención (un informa de batalla del "bloody captain"), Macbeth es descrito como alguien que abre y separa a cuerpos humanos como si fueran textiles: "desde ombligo a quijada lo desgarra / y pone su cabeza en las almenas" (I, 2, 22f.). Esta es, por un lado, una anticipación del motivo de la cesárea y, con esto, una alusión a Macduff, que superaría a Macbeth, por el otro, es una imagen para el cortar todo vínculo humano ("those strong knots of love" - IV, 3, 27), algo que caracteriza al solitario asesino Macbeth. También su mujer parece haber dañado, en sus fantasías, al mismo tejido del mundo:

32 Se agrega a lo anterior un aspecto heráldico del significado del martlet: en el simbolismo blasónico inglés esta es la "cadency mark" (signo de diferenciación) del cuarto hijo. Macbeth ni siquiera tiene uno.

33 Se trata de una asignación heráldica ex post: Edward recién es identificado a partir del siglo XIII con este blasón (Boutell \& Fox-Davies 2014, p. 18). 
Come, thick Night,

And pall thee in the dunnest smoke of Hell,

That my keen knife see not the wound it makes,

Nor Heaven peep through the blanket of the dark,

To cry, >Hold, hold!^

$(\mathrm{I}, 5,50-54)^{34}$.

\section{PECHO BUENO - PECHO MALO}

Luego de esta visión panorámica que abarca el complejo metafórico 'dormirleche-tejido' gradualmente se vuelve claro cómo se relaciona el motivo del dormir con las fantasías de perversa maternidad que son escenificadas en Macbeth. El tejido damnificado del dormir establece una asociación con el contexto relacional elemental entre madre e hijo, que no representa a cualquier relación, sino su condición de posibilidad, el fundamento de relaciones objetales como tal. El entrecortar este contexto relacional elemental aquí es escenificado incesantemente. En vez de "la leche de la bondad humana" son otros líquidos los que se intercambian: "Hie thee hither, / That I may pour my spirits in thine ear"'35, dice Lady Macbeth (I, 5, 24), mientras que el balance final de Macbeth es: "I have supp'd full with horrors"36 (V, 5, 13). Este ataque a un vínculo ${ }^{37}$, que en cierto sentido es la conexión con el mundo por antonomasia, produce la pesadilla.

Con tal de ilustrar lo anterior, tengo que introducir algunos conceptos que provienen del pensamiento de Melanie Klein. Este pensamiento, a pesar de la reticencia y del cuidado con que en el ámbito de las letras ha sido recepcionado, de una manera que resulta casi ominosa es apropiado para arrojar luz sobre el "mundo de Macbeth". El hecho de que este mundo sea

$34 \quad$ “iVen, noche espesa, ven / y ponte el humo lóbrego de los infiernos / para que mi ávido cuchillo no vea sus heridas, / ni por el manto de tinieblas pueda el cielo asomarse / gritando, ¡basta, basta!”.

35 Ven pronto, ven, para que pueda / vaciarte mi coraje en tus oídos.

$36 \quad$ Ya estoy saciado por atrocidades.

$37 \quad C f r$. Bion, Wilfred. Angriffe auf Verbindungen. In: Spillius, E.B. (Hg.): Melanie Klein heute. Tomo 1: Beiträge zur Theorie (110-129). trad E. Vorspohl. München, Wien: Verlag Internationale Psychoanalyse), 1990a (1959). 
interpretable con Melanie Klein ${ }^{38}$, no reduce su horror, sino que más bien lo intensifica. Los conceptos kleinianos, como es consabido, eran el resultado de un esfuerzo de por vida de encontrar una lengua, mejor dicho, una mitología, en la que deja describirse el mundo interno de niños muy pequeños. Es un mundo arcaico, preedípico, en el que parecieran acontecer cosas extrañas, prelingüísticas - "acción sin nombre", como dicen las brujas (IV, 1, 49). Cuando Jacques Lacan llamó a Melanie Klein una "carnicera (de interiores) inspirada" (una tripière inspirée) (Lacan, Jeunesse 750; cfr. Kristeva 225), aparentemente seguía asociaciones parecidas, porque con esto la colocó en las cercanías de las "Weïrd Sisters" con su caldero de interiores abyectos. Mientras que lo inconsciente según Freud consiste en lo esencial de mociones y conflictos pulsionales reprimidos, Klein se centra sobre todo en fantasías inconscientes respecto de ciertas relaciones. Según ella, el sujeto desde su nacimiento está poblado por "objetos internos" que pueden describirse como personas independientes con buenas y malas intenciones respecto de dicho sujeto. De este modo, los textos de Klein despliegan un mundo de buenos y malos objetos, cuyo incesante drama interno, cuyas transformaciones y mecanismos influyen profundamente la vida relacional consciente del sujeto.

El objeto primordial de este mundo interno, de acuerdo a Melanie Klein, es el pecho materno. En Notes on some schizoid mechanisms dice: "I have often expressed my view that object-relations exist from the beginning of life, the first object being the mother's breast which to the child becomes split into a good (gratifying) and bad (frustrating) breast; this splitting results in a severance of love and hate" (2).

Y: "The destructive impulse is partly projected outwards (deflection of the death instinct) and, I think, attaches itself to the first external object, the mother's breast" (10). En este nivel temprano del desarrollo del yo el mecanismo de la escisión juega un rol fundamental, que luego le corresponderá a la represión (p. 2f). Porque este mundo arcaico solo puede ser estabilizado, hasta cierto punto, a través de la escisión, es decir, a través de la proyección de todos los impulsos destructivos así como de las resultantes angustias persecutorias, angustias de descomposición, angustias de ser destruido desde el interior ("O! full of scorpions is my mind" - Macbeth III, 2, 36). Según Klein (p. 6),

38 Tales interpretaciones, no obstante, escasean. Si bien Roberts (1975) opera con algunos conceptos kleinianos, sin embargo, justamente en su lectura de Macbeth (p. 206-211) los deja de lado. Sobre el concepto del "mundo de Macbeth", cfr. McElroy 1973, p. 207. 
el objeto interno bueno se convierte en foco del desarrollo del yo, el objeto malo actúa como agente de la desintegración del yo. Esta lucha se manifiesta, entre otros, en fantasías de ataque al objeto interno, que transcurren en dos direcciones: "one is the predominantly oral impulse to suck dry, bite up, scoop out and rob the mother's body of its good contents" (p. 8) (en el mundo de Macbeth: leche); "[ $\mathrm{t}]$ he other line of attack derives from the anal and urethral impulses and implies expelling dangerous substances (excrements) out of the self and into the mother" (p. 8) (en el mundo de Macbeth: bilis).

$\mathrm{O}$, así parece, Macbeth es una pieza muy kleiniana o hay más Macbeth en Melanie de lo que parece. De hecho, quiero afirmar que el texto de Shakespeare penetra un estrato de fantasías arcaicas que yace debajo del orden sexual socialmente sancionado y que necesariamente es interpretado mal cuando es visto solo a la luz de determinadas representaciones de roles de feminidad ${ }^{39}$. Lady Macbeth no es simplemente una fantasía misógina según el gusto de una época dedicada a la caza de brujas. Ella de manera chocante es lo que Melanie Klein llamó el pecho malo. La perversa escena de amamantamiento fantaseada por Lady Macbeth representa cómo un vínculo elemental con el mundo es vuelto hacia lo paranoide. El objeto malo atraviesa alborotadamente a toda esta tragedia, que como un todo representa un universo escindido. El mundo de Macbeth se caracteriza por el hecho de que la ambivalencia en ella no puede ser soportada: "Fair is foul, and foul is fair" 40 (Macbeth, I, 1, 10), así reza la fórmula para el susto al que, en tanto ultima ratio, reacciona la escisión ${ }^{41}$. Es un mundo respecto del cual uno solo puede establecer una relación cortando y matando, tal como lo hace Macbeth, mientras fantasea sus actos como un alisar y lijar este mundo: "I require a clearness - leave no rubs or botches in the work" 42 , instruye a sus sicarios (III, 1, 132f.). "I had else been perfect / Whole as the marble, founded as the rock" ${ }^{43}$ (III, 4, $20 \mathrm{f}$.)

39 Esto es el caso, por ejemplo, en Trubowitz 2012. Trubowitz si bien se refiere a Melanie Klein (p. 71), empero, no distingue entre fantasías inconscientes y estereotipos de género.

$40 \quad$ Lo bello es feo y feo es lo bello.

$41 \quad C f$. Trubowitz 2012, p. 93, para una interpretación histórico-política de esta ambivalencia: "A través del tropo del pecho materno, la obra transmite la ambivalencia cultural y el pánico fronterizo que caracterizan a ese momento histórico tan tenso.

42 Exijo quedar libre de sospecha... (sin dejar rastro ni señal de lo que hagáis).

43 Feliz hubiera sido en el caso contrario; / compacto como el mármol, firme como la roca. 
dice su deseo que nunca puede cumplirse, debido a que siempre aparecen nuevos "rubs and botches", nuevas chapuzas, que hay que erradicar. La escisión genera escisión, nunca es suficiente.

Los objetos buenos, en cambio, en este drama están marcados de manera tenue. Si bien el sanador rey Edward es anunciado en el acto 4, sin embargo, manda sus disculpas y no aparece. Los contrincantes de Macbeth, Malcolm y Macduff son, como ha sido observado con frecuencia, caracteres pálidos, más bien episódicos (McElroy 237). El aire puro y los martlets celestiales solo existen en la ilusión de Banquo. Pero sí hay un objeto que es provisto de los atributos del nutrir, del curar y de la misericordia. Es la primera víctima de Macbeth y en tanto perdida siempre sigue estando presente. Por muy extraño que pueda sonar: el objeto bueno por antonomasia en Macbeth es el dormir. El dormir, que a través de sus asociaciones con el pecho nutricio y el tejido protector es fantaseado, ante todo, como conexión - a saber, como conexión con un objeto interno bueno, de cuya existencia depende y en caso de cuya pérdida se hunde con éste. La metafórica de la maternidad pervertida en Macbeth simboliza el corte de este conjunto relacional, con lo que el retorno hacia el interior fantaseado, en el que moran los sueños, se torna imposible. Melanie Klein, con tal de recurrir una vez más a ella, distingue entre angustia de persecución, por un lado, y la angustia de perder a la madre respectivamente de destruirla, por el otro. Los dos tipos de angustia se encuentran en la pieza de Shakespeare. La primera es omnipresente, la segunda aparece en el grito de espanto: "Macbeth does murther sleep!".

\section{LA TRAGEDIA SONÁMBULA}

Ante este trasfondo, en un último paso, puede vincularse la pregunta por las relaciones de objeto fantaseadas con la pregunta por el rol de la pesadilla en esta tragedia. Porque lo que aquí al parecer asesina al dormir no es sino la pesadilla. Cuando el dormir presupone repliegue y sensación de protección, la pesadilla aparece como una suerte de autoexpulsión del sujeto de este estado. Si con Melanie Klein se entiende el sueño como el escenario de los objetos internos, entonces serían las pesadillas las que nos vuelven a arrojar hacia aquel tipo de estados primitivos de escisión, en los que los 'objetos malos' se imponen. Una representación interna de tales objetos en el drama de Shakespeare se encuentra, por lo visto, en el caldero de las brujas de las "Weïrd Sisters": un potaje de cuerpos despedazados, desde el que emergen 
diferentes imágenes -lo que aquí hierve es una sopa onírica. Las hermanas también exhiben rasgos de la night-hag, de la variante femenina del Nachtmahr o del Alp, de aquella figura que en el folclore germánico es responsable de los malos sueños y que también es citada por Shakespeare en otras partes ${ }^{44}$.

Stephen Greenblatt ha defendido la tesis de que el autor de Macbeth se reserva para él mismo la posición de la bruja (Greenblatt 1994, p. 36). Si es que Shakespeare adopta el lugar de la bruja, entonces, quisiera complementar, su pieza es el caldero. Y esto es dicho con toda seriedad: Una tragedia como ésta posee la función de admitir representaciones de fantasías persecutorias y de objetos malos - pero, al mismo tiempo, también ha de crear, a través de la trama y del lenguaje, un contenedor para todo esto. Podría llamarse a semejante tragedia una "paranoia dirigida", con tal de retomar una expresión con la que Lacan caracterizaba el análisis kleiniano (Lacan, Jeunesse 109). Lo que a primera vista parece un burbujeante caldero, lleno de fantasías malignas, a la segunda resulta ser una estructura que justamente vuelve simbolizables y representables a estas fantasías. Si es que pudiera existir una poética de la pesadilla, entonces tendría que ser esto - un arte del contener o abstenerse [eine Kunst des Enthaltens] (cfr. Bion, Lernen 90f.). En el caso de Macbeth, este arte consiste en incluir un actuar, que apenas puede ser llamado así, porque más bien se asemeja a un caer hacia adelante, a pesar de ello en una trama dramática. A partir de un punto, que puede ser determinado con exactitud, al interior de esta trama, a saber, después de haber mirado hacia el interior del caldero de las brujas, Macbeth cae en una especie de patología de la acción inmediata:

The flighty purpose never is o'ertook, Unless the deed go with it. From this moment, The very firstlings of my heart shall be

The firstlings of my hand $(\mathrm{IV}, 1,145-148){ }^{45}$

Donde los primerizos del corazón son los de la mano, ya ni puede hablarse de "actuar" en el sentido ético de la palabra. Se trata, más bien, de un tipo de "passage à l'acte", del paso directo desde la fantasía a la acción, de la

44 Cfr. Romeo and Juliet, I, 4, 92, así como King Lear, III, 4, 117-121.

45 El propósito fugaz no llega a ejecutarse / sino acompañado por hechos. Desde ahora / el principal deseo de mi corazón será / el deseo principal de mi mano. 
suspensión del espacio intermedio imaginario entre el deseo y la acción. Ya hace tiempo que el pensar para Macbeth solo era "torture of the mind" (III, $2,21)$, un insoportable estadio intermedio entre dos acciones. Ahora está en vías de abolir del todo a aquel intermedio. Pero también esta pérdida tiene que ver con la suspensión del soñar: "Basta ya de visiones" es, de ahora en adelante, la divisa (IV, 1, 155). Y, en efecto, a partir de ahora para Macbeth ni siquiera habrá alucinaciones, sino ya tan solo fantasías realizadas, bosques que realmente pasan al ataque. Esta tragedia no es, como con frecuencia se ha dicho, el drama de la imaginación exaltada de Macbeth, de lo contrario, precisamente trata de la desaparición de aquella tierra intermedia en la que las fantasías pueden ser soportadas y reelaboradas.

Paradojalmente, de la negativa de Macbeth a la tierra intermedia entre impulso y acto no surge una lucidez carente de ilusiones ${ }^{46}$, sino una clase de proceder en trance, un actuar sonámbulo. Lady Macbeth no es la única sonámbula en esta pieza. Su escena de sonambulismo posee una función emblemática para el drama como un todo, incluyendo al protagonista. Porque lo ominoso del sonambulismo es justamente la superación de la inhibición motriz que habitualmente convierte al dormir en un lugar seguro. En la sleep walking scene de Lady Macbeth el drama representa la pérdida de esta inhibición de la acción y, al mismo tiempo, lleva el luto por ella. Lo que exhibe la escena del sonambulismo es un actuar sin conciencia, una propagación de la pesadilla al mundo del actuar, tal como -así podría pensarse- ni siquiera el teatro se lo puede permitir.

Si es que el soñar tradicionalmente ha sido considerado como metáfora para el teatro, esto es así porque, en tanto forma lúdica del pensar, en el lugar seguro del dormir posee la función de volver superfluo semejante irrupción hacia el actuar. Lo más bello y lo peor puede ser ensayado en este lugar sin incidir - por la vía motriz- en la realidad. El sueño protege a la realidad de nuestras fantasías. Pero en el caso del sonambulismo es justamente el sueño el que produce tal irrupción. Quien ahora aún quiera terminar el actuar, tiene que despertar al soñante. Si el actuar del actor en el escenario ya no es equiparado metafóricamente con un sueño, sino con el caminar dormido, entonces la distinción del interior y del exterior comienza a tambalearse y, con ella, lo hace el mismo concepto del teatro: ¿Quizá la trama contemplada

46 Tal como Shakespeare la exhibió a través del cínico Gloucester (Richard III), que, sin embargo, a diferencia de Macbeth, hasta su fin no deja de soñar. 
no es un sueño que el espectador soñó (como dice al final de Midsummer Night's Dream), sino un actuar inconsciente que no tiene bajo control? Así el problema del despertar, que convencionalmente es equiparado al fin de la obra teatral, vuelve a plantearse de manera inquietante.

Semejante 'despertar' de la ilusión teatral, podría pensarse, acontece en el clímax nihilista de la tragedia de Shakespeare, en el último monólogo del héroe. Este monólogo describe la devaluación del mundo después del cortarse de todas las relaciones, incluso de las más elementales:

Out, out, brief candle!

Life's but a walking shadow; a poor player,

That struts and frets his hour upon the stage,

And then is heard no more: it is a tale

Told by an idiot, full of sound and fury,

Signifying nothing ${ }^{47}$

$(\mathrm{V}, 5,23-28)$.

Si es que hay un momento en esta tragedia en el que la pesadilla no solo actúa, sino que es nombrada por su nombre, sería éste: la caída hacia el sinfondo, el vacío como línea de base de toda angustia soñada se articula aquí. Pero no se trata en absoluto de 'despertar'. Más bien, este monólogo describe el punto en el que todos los atributos del sueño se traspasaron a la vida. Volatilidad y olvido ("walking shadow", "heard no more"), carácter escénico ("poor player"), estructura narrativa ("a tale"), confusión ("told by an idiot"), afectos amenazantes ("full of sound and fury"), ininterpretabilidad ("signifying nothing"). Todavía hay que constatar: dado que no puede soñarse, la vida en vigilia adopta rasgos sonámbulos.

Al mismo tiempo, se torna evidente que la tragedia tiene que ser, ella misma, un suplemento del sueño suprimido. Porque, al igual como la escena del sonambulismo con la que se corresponde directamente, también este monólogo es un clímax de autorreferencia teatral. No obstante, al dejar que su drama remita a sí mismo, Shakespeare juega un juego peligroso: pone en boca de Macbeth un epílogo prematuro -un epílogo que vacía y desvaloriza todo lo que vimos. Así no puede terminar. Y tampoco termina, porque la

47 ¡Extínguete, fugaz antorcha! / La vida es una sombra tan sólo, / que transcurre; un pobre actor que, / orgulloso, consume su turno sobre el escenario / para jamás volver a ser oído. Es una historia / contada por un necio, llena de ruido y furia, / que nada significa. 
trama sigue un poco más. Y, en cierto sentido, sí termina así, porque nada de lo que sigue, en cuanto a su potencia retórica, puede medirse ni siquiera aproximadamente con estas líneas. Menos la palabra final, del todo pragmática, que pronunciará Malcolm, el nuevo rey, al final. Hace parte del ritmo sin aliento de esta tragedia que su epílogo se anticipe en demasía y así se convierta en parte de la trama -como una escena del despertar soñada, que solo está ahí para postergar un poco más el despertar propiamente tal. La tragedia se da el tiempo para volver a componer el orden del mundo; pero esto sucede apresuradamente, casi a regañadientes: un arreglo de emergencia del mundo y de la forma dramática.

\section{BIBLIOGRAFÍA}

Bion, Wilfred. "Angriffe auf Verbindungen". In Spillius, E.B. (Hg.): Melanie Klein heute. Tomo 1: Beiträge zur Theorie (110-129). Trad E. Vorspohl. München, Wien: Verlag Internationale Psychoanalyse, 1990a (1959).

Lernen durch Erfahrung. Trad. E. Krejci. Frankfurt/M.: Suhrkamp, 1990b (1962).

Booth, Stephen. King Lear, Macbeth, Indefinition and Tragedy. New Haven, London: (Yale University Press, 1983.

Boutell, Charles \& Fox-Davies, Arthur Charles. Handbook to English Heraldry. London: Reeves \& Turner, 2014.

Cioran, Emil M. Die verfehlte Schöpfung. Trad. F. Bondy. Frankfurt/M.: Suhrkamp, 1979 (1969).

De Quincey, Thomas. Über das Klopfen an der Pforte in Shakespeares Macbeth. Ein Essay. Englisch und deutsch. Ed. y trad. B. Erenz. Berlin: Friedenauer Presse, 1986 (1823).

Ewbank, Inga-Stina. "The fiend-like queen: A note on Macbeth and Seneca's Medea”. Eds. K. Muir \& P. Edwards. Aspects of Macbeth (53-65). Cambridge: Cambridge University Press, 1977.

Freud, Sigmund. Die Traumdeutung. Gesammelte Werke, tomos 2/3. Frankfurt/M.: Fischer, 1900. Der Dichter und das Phantasieren. Gesammelte Werke, tomo 7 (213-223). Frankfurt/M.: Fischer, 1908.

Einige Charaktertypen aus der psychoanalytischen Arbeit. Gesammelte Werke, tomo 10 (364-391). Frankfurt/M.: Fischer, 1916.

Jenseits des Lustprinzips. Gesammelte Werke, tomo 13 (1-69). Frankfurt/M.: Fischer, 1920.

Greenblatt, Stephen. "Shakespeare bewitched". Eds. T. Kishi, R. Pringle \& S. Wells. Shakespeare and Cultural Traditions (17-42). Newark: University of Delaware Press, 1994.

Hartmann, Ernest. Dreams and Nightmares: The New Theory on the Origin and Meaning of Dreams. New York: Perseus Publishing, 2001 (1998). 
Klein, Melanie. Bemerkungen über einige schizoide Mechanismen. 1946. Gesammelte Schriften, Bd. 3. (1-41). Stuttgart-Bad Cannstatt: frommann-holzboog, 2000.

Koppenfels, Martin von. "Ein Schloss am Meer. Freuds Traum vom `Frühstücksschiff^ und das Affektkapitel der Traumdeutung". Psyche - Z Psychoanal 66, 2012: 968-991.

“Gibt es eine Poetik des Alptraums?" Eds. A. Avanessian \& N. Howe. Poetik. Historische Narrative und aktuelle Positionen. Berlin: Kadmos, 2014: 30-45.

Krakow, B., R. Kellner, D. Pathak \& L. Lambert. "Long term reduction of nightmares with imagery rehearsal treatment". Behavioural and Cognitive Psychotherapy 24, 1996: 135-148.

Kristeva, Julia. Das weibliche Genie. Melanie Klein. Trad. J. Naumann. Gießen: PsychosozialVerlag, 2008 (1999).

Lacan, Jacques. “Jeunesse de Gide”. Écrits (739-764). Paris: Seuil, 1966.

"L'aggressivité en psychanalyse". Écrits. Paris: Seuil. 1966. 101-124.

Lesser, Simon O. "Macbeth - Drama and dream". Ed. J. Strelka. Literary Criticism and Psychology. London: Pennsylvania State University Press, 1976. 150-173.

McElroy, Bernard. Shakespeare's Mature Tragedies. Princeton: Princeton University Press, 1973.

Muir, Kenneth. "Introduction \& Commentary”. Shakespeare (1984 [1623]): Macbeth. London, New York: Methuen, 1984.

Noll, Marcus. An Anatomy of Sleep. Die Schlafbildlichkeit in den Dramen William Shakespeares. Würzburg: Königshausen \& Neumann, 1994.

Roberts, Patrick. The Psychology of Tragic Drama. London, Boston: Routledge \& Kegan Paul, 1975.

Shakespeare, William. Macbeth. Trad. L. Tieck. Sämtliche Werke, Bd. 5. Berlin: Verlag Literatur und Kunst, 1927 (1623).

Macbeth. Ed. K. Muir. (The Arden Shakespeare). London, New York: Methuen, 1984 (1623).

Macbeth. Trad. F. Günther. Cadolzburg: ars vivendi, 2001 (1623).

King Henry IV, Part 2. Ed. A.R. Humphreys (The Arden Shakespeare). London: Methuen, 2005 (1623).

Trubowitz, Rachel. Nation and Nurture in Seventeenth-Century English Literature. Oxford: Oxford University Press, 2012.

Weidhorn, Manfred. Dreams in Seventeenth-Century English Literature. The Hague, Paris: Mouton, 1970.

Willbern, David. "Phantasmagoric Macbeth". English Literary Renaissance 16, 1986: 520-549.

Wilson Knight, George R. The Imperial Theme: Further Interpretations of Shakespeare's Tragedies Including the Roman Plays. Oxford: Oxford University Press, 1931. 